
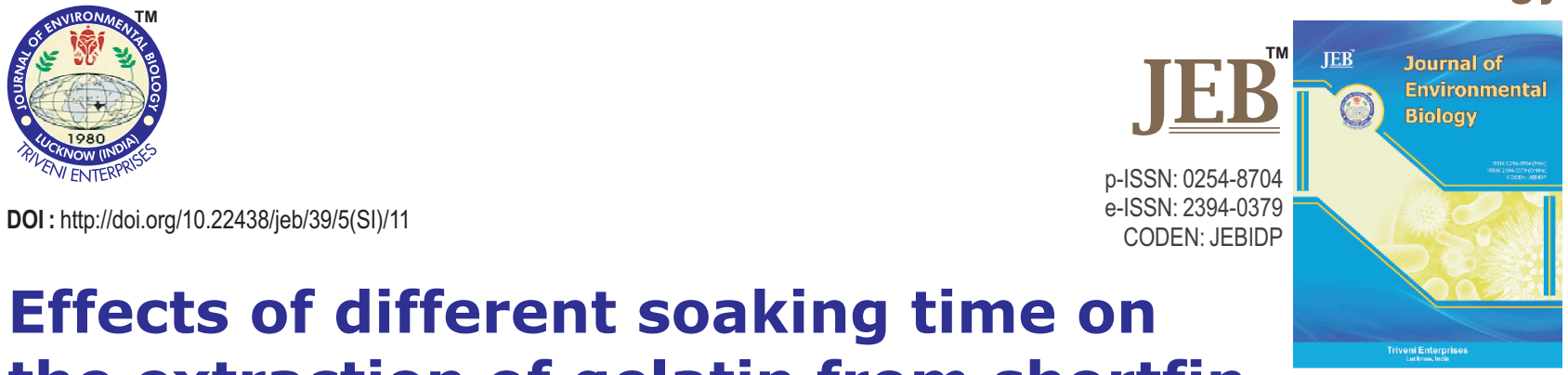

\title{
Effects of different soaking time on the extraction of gelatin from shortfin scad (Decapterus macrosoma) heads
}

\section{Authors Info \\ C.Y. Kuang and N.F. Mohtar* \\ School of Fisheries and Aquaculture Sciences, Universiti Malaysia Terengganu, 21030 Kuala Nerus, Terengganu, Malaysia \\ *Corresponding Author Email : fazliyana@umt.edu.my}

Key words

Decapterus macrosoma

Fish by-products

Fish gelatine

Soaking time

Publication Info

Paper received : 15.08 .2017

Revised received : 20.09.2017

Re-revised received : 05.11.2017

Accepted : 28.12.2017

\begin{abstract}
Aim: Fish gelatin is one of the potential biopolymers that can be extracted from the connective tissues of any fish by-products such as skin, scale, bone, head, fin and frame. This study was carried out to optimise the best method of gelatin extracted from the heads of Shortfin scad (Decapterus macrosoma), further the effects of different soaking time on the physico-chemical properties of extracted gelatins was also determined.

Methodology: The heads of shortfin scad (Decapterus macrosoma) were collected from fish processing industries and were cleaned prior to extraction. The cleaned heads of $D$. macrosoma were subjected to different soaking times $(1,4,8$ or $12 \mathrm{hrs})$ in $0.1 \mathrm{M}$ citric acid. Prior to these soaking times, the heads were placed in boiling water to remove excess flesh and the pre-treated with $0.2 \mathrm{M}$ of sodium hydroxide solution for one hour, rinsed with tap water, soaked in $0.05 \mathrm{M}$ of sulphuric acid for one hour and were then rinsed with tap water.
\end{abstract}

Results: Results showed the optimum soaking time of $D$. macrosoma heads was obtained at $8 \mathrm{hr}$ with the highest yield value of $1.70 \%$, which was significantly higher compared to those soaked at 1,4 or $12 \mathrm{hr}$ $(p<0.05)$. The moisture, crude protein, lipid and ash of the gelatins were $9.08 \%, 15.25 \%, 0.46 \%$ and $41.03 \%$, respectively. The $\mathrm{pH}$ in the extracted gelatin was obtained at 3.31 . Gel strength and melting point of $D$. macrosoma heads gelatin were found at $19.68 \mathrm{~g}$ and $16.0^{\circ} \mathrm{C}$, respectively, lower than that of bovine gelatin $\left(300.5 \mathrm{~g} ; 37.0^{\circ} \mathrm{C}\right)$, respectively. The ratio of imino acids in gelatin from $D$. macrosoma heads to bovine gelatin was 46 residues to 132 residues per 1000 total amino acid residues.

Interpretation: The findings suggested that gelatin extracted from the heads of $D$. macrosoma can be potentially applied in many areas due to its comparable properties with the commercial gelatin.

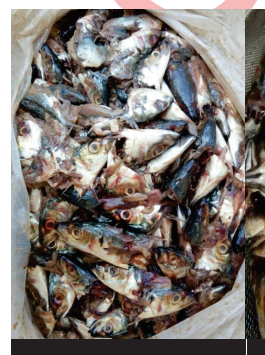

Raw fish heads

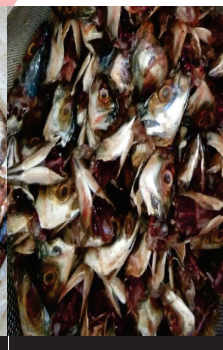

Removal of gills

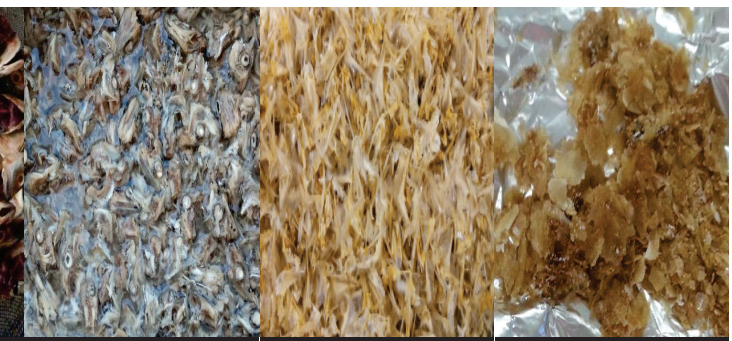

Removal of eyes and excessive flesh 


\section{Introduction}

Gelatin is one of the most popular biopolymers and due to unique functional properties, it is extensively used in wide variety of applications, such as in food, pharmaceuticals, cosmetics and photographic areas (Karim and Bhat, 2009). The global demand for gelatin has been increasing over the years. Currently, the annual world output of gelatin is approximately 326,000 tons, with pig skin-derived gelatin contributing the highest (46\%), followed by bovine hides $(29.4 \%)$, bones $(23.1 \%)$ and other sources $(1.5 \%)$ (Karim and Bhat, 2009). Gelatin is water-soluble polymer that can be used as an ingredient in food industry to improve the elasticity, consistency and emulsion stability of foods (Tavakolipour, 2011). It is widely used in jelly production and as emulsifiers, micro-encapsulating agents and colloid stabilizers in food industries. In the pharmaceutical and medical fields, gelatin is widely used in the manufacture of hard and soft capsules. It is also used as a matrix for implants, plasma expanders in injectable drug delivery microspheres, and in intravenous infusions (Kim and Wijesekara, 2012). In cosmetic industry, gelatin has been used for many years as hydrolyzed animal protein in shampoos, conditioners, lipsticks and nail formulas (Kim and Wijesekara, 2012).

Gelatin is derived from fibrous protein collagen by partial hydrolysis. Collagen can be found in skin, bones, tendons and cartilage, which consists of a triple-helix structure composed of three a-chains intertwined and bonded by inter-chained hydrogen bonds. Collagen is the major structural component of connective tissue proteins with up to $30 \%$ of the total protein in the body tissue of vertebrates and invertebrates, consisting the following amino acids such as glutamine, hydroxyproline and proline (Darmanto et al., 2014). Bovine and porcine collagen are the main industrial sources, but fish collagen can be a useful alternative due to their excellent characteristics (Liu et al., 2007).

Alternative sources of gelatin are gaining prominence, especially gelatin extracted from the by-products (skins, bones, heads, scales, and frames) of marine fish species (GómezGuillén et al., 2009). This has encouraged researchers to explore this resource. Moreover, fish gelatin shows analogous characteristics to porcine gelatin, and thus can be considered as a substitute to mammalian gelatin in the food industry (Mohtar et al., 2010; Kim and Venkatesan, 2014).

Fish cracker (Keropok lekor) is a traditional Malaysian fish product and it is a popular snack food that is widely consumed by all communities in Malaysia. It is famous, especially in the East coast of Peninsular Malaysia such as Terengganu, Kelantan and Pahang. Generally, fishes used in keropok lekor production are mainly low value pelagic fish, such as Chirocentrus dorab, Decapterus macrosoma and Sardinella fimbriata. According to a local keropok lekor in Terengganu, ikan D. macrosoma is the best fish to be used for making keropok lekor due to its sweet taste and lower amount of bones (Omar et al., 2008).

High amount of waste are produced from the expanding fish processing industries. Malaysians are among the world's top fish consumers, eating at least $56.5 \mathrm{~kg}$ of fish per person each year (The Star Online, 2014). Utilization of fish waste to produce gelatin will increase their commercial value and help reduce the adverse environmental problems. The waste produced from fish processing industry can occupy as much as $75 \%$ of the total fish catch weight (López-Caballero et al., 2013). This huge amount of fish waste disposal may cause health and environmental problems. Historically, fish by-products are simply disposed because it is recognized as being low value (Kim and Venkatesan, 2014). However, fish waste can be a source of potential ingredients application to the food and others industry. The physical and chemical properties of gelatin depends on the raw materials of extracted species and on the processing condition of gelatin manufacturing (Gómez-Guillén et al., 2009). Nevertheless, the yield of gelatin may be affected by the pretreatment and extraction process, which depends on the $\mathrm{pH}$, temperature and soaking time. The important functional properties of gelatin consist of gel strength, melting temperature and viscosity, which is generally related to their gelling characteristics. From previous studies conducted on the soaking time, researchers demonstrated the importance of pre-treatment time and several condition factors on the yield and quality of gelatin as shown in grass carp (Kasankala et al., 2007), shark (Cho et al., 2004), cuttlefish (Ninan et al., 2015), rainbow trout (Tabarestani et al., 2010), as well as chicken feet (Liu et al., 2011) and chicken shank bones (Puspitasari et al., 2013). Therefore, it is necessary to determine the optimum pretreatment conditions, such as soaking time in citric acid solution, to extract gelatin in fish by-products. In view of the above, the present study was carried out investigate the effects of different soaking time on gelatin yield from Shortfin Scad (Decapterus macrosoma) heads and to determine some of the physico-chemical properties of extracted gelatin with optimum soaking time during the extraction procedure.

\section{Materials and Methods}

Raw material: A total of $50 \mathrm{~kg}$ of Decapterus macrosoma heads were purchased from a fish processing plant, Maperow Sdn. Bhd. in Terengganu, Malaysia. The heads were washed with tap water and then the attached flesh on the fish heads were removed in boiling water and then any excess remaining flesh was scraped off with a knife. The remaining samples were kept at $-20^{\circ} \mathrm{C}$ until further use.

Gelatin extraction: Gelatin was extracted from the cleaned samples following the method of Gudmundsson and Hafsteinsson (1997) with some modifications. Samples of cleaned fish heads were pre-treated by soaking in a $250 \mathrm{ml}$ beaker containing $0.2 \mathrm{M}$ of sodium hydroxide solution for one 
hour with subsequent rinsing with tap water to $\mathrm{pH}$ 7. The treatment was repeated twice. The fish heads were then soaked with $0.05 \mathrm{M}$ of sulphuric acid for one hour with subsequent rinsing with tap water. The fish heads were then soaked with $0.1 \mathrm{M}$ citric acid for one hour with subsequent rinsing with tap water. The acidic solutions were drained off and the samples were washed with running water until a $\mathrm{pH}$ of 7 was maintained. The experiments were repeated by replacing one hour of soaking time in citric acid with 4, 8 and $12 \mathrm{hrs}$. The ratio of fish heads to washing liquid was $1 \mathrm{~kg}$ fish heads (dry weight) to 7 I of acid or alkali solution for each treatment.

The fish heads were washed with distilled water in 1:3 to remove any residual substances and were then extracted with distilled water at $45^{\circ} \mathrm{C}$ for $12 \mathrm{hrs}$. The mixture was filtered and dried in an oven at $60^{\circ} \mathrm{C}$ overnight. The dried gelatin was crushed into powder by using a pestle and mortar and then stored in airtight containers. All treatments were repeated three times at each soaking time.

Proximate analysis: The proximate analysis of gelatin extracted from Decapterus macrosoma heads were carried out according to the procedures of AOAC (2000).

Gelatin $\mathrm{pH}$ : The $\mathrm{pH}$ of extracted gelatin was determined according to See et al. (2010). A total of $0.667 \mathrm{~g}$ of dry gelatin was dissolved in $10 \mathrm{ml}$ of distilled water at $60^{\circ} \mathrm{C}$ for $30 \mathrm{~min}$. The gelatin solution was cooled to room temperature for $30 \mathrm{~min}$, and a pH meter was used to determine the $\mathrm{pH}$ at $25^{\circ} \mathrm{C}$.

Gel strength : The gel strength of extracted gelatin was determined according to BSI (1975). A6.67\% gel was prepared in a beaker by dissolving $0.334 \mathrm{~g}$ of dry gelatin in $5 \mathrm{ml}$ of distilled water at $60^{\circ} \mathrm{C}$ for $30 \mathrm{~min}$. The solution was cooled in room temperature for $30 \mathrm{~min}$ and then chilled in a refrigerator at $7^{\circ} \mathrm{C}$ for $18 \mathrm{hrs}$. The gel strength was measured immediately after being removed from a refrigerator using a TA.XT Texture Analyzer. The texture analyzer was equipped with a load cell of $5 \mathrm{~kg}$, cross-head speed $1 \mathrm{~mm} \mathrm{sec} c^{-1}$ and was equipped with a flat bottomed plunger that was 0.5 inches in diameter. The beaker was placed centrally under the plunger for the penetration test. The probe proceeded to penetrate the gel at $4 \mathrm{~mm}$ depths and the maximum force $(\mathrm{g})$ was determined.

Melting point : The melting point was conducted according to Muyonga et al. (2004) with some modifications. Gelatin of $6.67 \%$ was prepared in a glass vial by dissolving $0.334 \mathrm{~g}$ of dry gelatin in $5 \mathrm{ml}$ of distilled water. This mixture was dissolved at room temperature for $30 \mathrm{~min}$ and then heated in a water bath at $60^{\circ} \mathrm{C}$ for another $30 \mathrm{~min}$. The dissolved samples were cooled at room temperature for $30 \mathrm{~min}$, and then chilled in a refrigerator at $7^{\circ} \mathrm{C}$ for $18 \mathrm{hrs}$. The samples were transferred into a water bath at $10^{\circ} \mathrm{C}$ and inverted. The water bath was warmed gradually by adding warm water at about $1^{\circ} \mathrm{C}$ per min. The temperature was recorded at which the gel melted.
Amino acid composition: The amino acid composition of Decapterus macrosoma head and bovine (control) gelatins were analyzed following on the method of Villas-Bôas et al. (2003), using gas chromatography-mass spectrometry (GC-MS). Three processes involved included hydrolysis, derivatisation, and injection of methyl chloroformate derivatised gelatins on the GCMS. A total of $5 \mathrm{mg}$ of gelatin sample was hydrolysed and incubated in $1 \mathrm{ml}$ of $6 \mathrm{~N}$ hydrochloric acid at $110^{\circ} \mathrm{C}$ for $12 \mathrm{hrs}$. The hydrolysed gelatin was transferred into a $1.5 \mathrm{ml}$ eppendorf tube and was then dried using nitrogen gas. The hydrolysed gelatin was derivatised by using methyl chloroformate method for the analysis by GC-MS. The hydrolysed gelatin was dissolved in $10 \mu \mathrm{l}$ with $10 \mathrm{mM}$ internal standard (d4-Alanine) and $190 \mu \mathrm{l}$ of $1 \mathrm{M}$ sodium hydroxide solution. This mixture was transferred to a $5 \mathrm{ml}$ silanised reaction tube and $167 \mu \mathrm{l}$ of methanol and $34 \mu \mathrm{l}$ of pyridine were added to the suspended solution. To initiate the derivatisation process, $20 \mu$ lof methyl chloroformate was added to the solution, followed by vortexing for $30 \mathrm{sec}$. Next $20 \mu \mathrm{l}$ of MCF was then added, followed by mixing for another $30 \mathrm{sec}$. A volume of $400 \mu \mathrm{l}$ of chloroform was immediately added to the reaction mixture and was mixed vigorously for $10 \mathrm{sec}$. This mixture was then centrifuged at $2000 \mathrm{rpm}$ for $2 \mathrm{~min}$ at room temperature to achieve better separation of two layers. The upper aqueous layer was discarded whereas the organic lower layer was dehydrated by adding $100 \mathrm{mg}$ of anhydrous sodium sulphate. An aliquot of 1 $\mu$ lof dried organic phase was injected into the GC-MS.

The data were analyzed by using analysis of variance (ANOVA). Comparison of means were performed by using SPSS version 20.

\section{Results and Discussion}

Gelatin yield obtained from different soaking time in citric acid : Pre-treatment time is an important factor that may affect the gelatin yield and associated properties. Increasing pre-treatment time (soaking time) generally increases gelatin yield (Tabarestani et al., 2010) and in this study, the gelatin yield increased from 1 to 8 hrs of soaking time (Fig. 1). This may be due to organic acid solubilizing the uncrosslinked collagens and breaking some of the inter-chain cross-linkages of collagens, thus leading to further collagen solubilization during extraction (Liu et al., 2015). An adequate number of cross-links must be broken to convert collagen into a suitable form for extraction (Zhou and Regenstein, 2005). Meanwhile, as for 1 and 4 hrs, the cross-linkage collagen fibers may not have been broken down completely.

However, the yield obtained for $D$. macrosoma heads did not show an increasing trend with increasing soaking time in citric acid. Gelatin yields of $D$. macrosoma heads reached a maximum gelatin yield at $8 \mathrm{hrs}$ of soaking time and declined at $12 \mathrm{hrs}$. Liu et al. (2001) also reported that gelatin yield did not increase continuously with increasing the soaking time in acetic acid, citric acid, hydrochloric acid or lactic acid. Meanwhile, a study on 


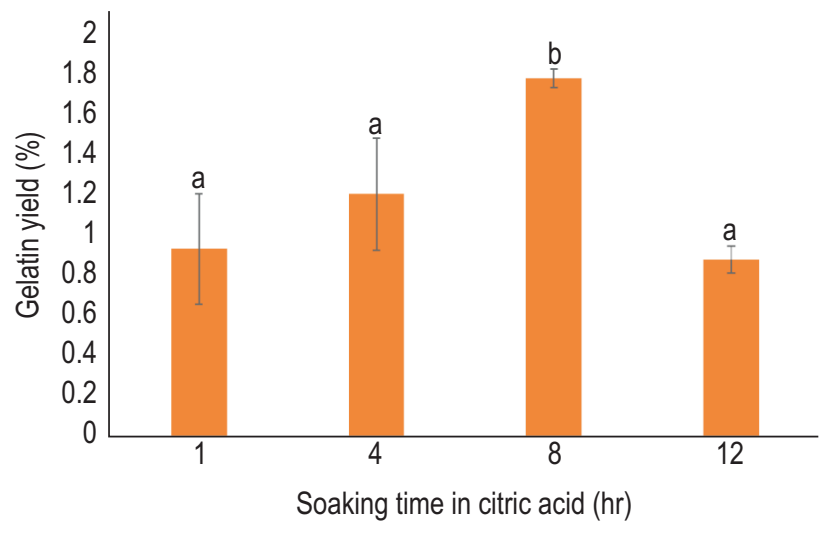

Fig. 1 : Mean gelatin yield obtained with different soaking times in citric acid. Values within a row with different letters are significantly different $(p<0.05)$

soaking chicken shank bones at different soaking times in hydrochloric acid solutions showed that the longest soaking time led to a lower collagen yield (Puspitasari et al., 2013). Low collagen yield will simultaneously lead to a low gelatin yield. The highest gelatin yield was obtained at $8 \mathrm{hrs}$ of soaking in citric acid, and the yield was significantly higher $(p<0.05)$ compared to other soaking times.

Gelatin yield : The gelatin yield obtained at 1, 4, 8 and $12 \mathrm{hrs}$ of soaking in citric acid were $0.89 \%, 1.15 \%, 1.70 \%$ and $0.84 \%$, respectively (Table 1). Although, $10 \mathrm{~g}$ of fish heads were used at each soaking time, less than $0.2 \mathrm{~g}$ of gelatin was produced. A total of $1034.5 \mathrm{~g}$ cleaned fish heads were further pretreated for $8 \mathrm{hrs}$ in citric acid for the characterization of gelatin and $17 \mathrm{~g}$ of gelatin was obtained. The yield obtained from $D$. macrosoma heads was $1.6 \%$, indicating a low yield, but was similar to the findings of Silva et al. (2011) who reported $1.54 \%$ gelatin yield from the carp head bones. A higher yield of gelatin extracted from $D$. macrosoma skin was $7.3 \%$ (Cheow et al., 2007). These differences in the yield could possibly be due to the differences in the amount of collagen and associated composition in the skin, bones, as well as their matrix components (Shakila et al., 2012).

A low gelatin yield exhibited in this study may be due to collagen leaching during the washing treatments, loss of collagen during extraction or incomplete conversion process of collagen to gelatine strands (Jamilah and Harvinder, 2002). The species and tissue not only affects the yield and quality of the gelatin, but also by the extraction process itself (Montero and Gómez-Guillén, 2000; Karim and Bhat, 2009). A higher gelatin yield and better gel characteristics were exhibited on extracted gelatin from Alaska pollock skin using a combination of alkaline pretreatments followed by acid pretreatments (Zhou and Regenstein, 2005). The obtained yield was also influenced by concentrations of sodium hydroxide, sulphuric acid and citric acid solutions used in the preliminary treatment of raw materials (Gudmundsson and
Table 1: Gelatin yield for each soaking time in citric acid

\begin{tabular}{ll}
\hline Soaking time in citric acid & Gelatin yield (\%) \\
\hline $1 \mathrm{hr}$ & $0.89 \pm 0.2623^{\mathrm{a}}$ \\
$4 \mathrm{hr}$ & $1.15 \pm 0.2665^{\mathrm{a}}$ \\
$8 \mathrm{hr}$ & $1.70 \pm 0.0451^{\mathrm{b}}$ \\
$12 \mathrm{hr}$ & $0.84 \pm 0.0643^{\mathrm{a}}$ \\
\hline
\end{tabular}

Values are mean of replicates \pm SD; Different letters indicate significant differences $(p<0.05)$

Hafsteinsson, 1997). Furthermore, the method of Gudmundsson and Hafsteinsson (1997) may not be optimal to extract gelatin from $D$. macrosoma heads and more research in this area is needed.

Proximate composition and $\mathrm{pH}$ : The proximate composition of D. macrosoma heads for moisture, crude protein, crude fat and ash were $9.08 \%, 15.25 \%, 0.46 \%$ and $41.03 \%$, respectively. The moisture content obtained from $D$. macrosoma heads conducted in this study was similar to common carp head bones, as well as D. macrosoma skins and channel catfish head bones in previous studies (Silva et al., 2011; Cheow et al., 2007; Liu et al., 2009). Commercial gelatins have moisture content between $8 \%$ and $13 \%$ (GMIA, 2012), as well as the moisture content of edible gelatin is between $8 \%$ and $15 \%$ (GME, 2005). The ideal humidity in gelatin is $8-12 \%$ and a moisture content above $16 \%$ is not desirable due to the risk of microbial growth (Almeida and Lannes, 2013). The moisture content of gelatin from $D$. macrosoma heads was $9.08 \%$, which was within the range of GMIAand GME standards. Gelatin extracted from D. macrosoma heads exhibited relatively low protein content when compared with other studies as shown in the Table 2. The gelatin extracted from $D$. macrosoma heads was almost free of fat $(<0.5 \%)$. The low lipid content in the gelatin from $D$. macrosoma heads may be related to the alkaline treatment, which might have been enough to remove lipids (Silva et al., 2011). The ash content obtained from D. macrosoma heads gelatin was high and this result is similar to common carp head bones reported in previous study (Silva et al., 2011). The high ash content in the gelatin obtained may be due to the combination of higher mineral content (Shakila et al., 2012) and low concentration of the acid used (Saneai et al., 2013). The bones usually contained higher ash content and lower moisture content than skins.

The $\mathrm{pH}$ of gelatin solution obtained was strongly acidic (3.31) and, this may be affected by the washing treatment (Jakhar et al., 2012). Cheow et al. (2007) reported that the skin gelatin $D$. macrosoma had pH 4.87 which was acidic. The $\mathrm{pH}$ obtained in this study was also strongly acidic and demonstrated slight difference compared to previous studies.

Gel strength, melting point and amino acid composition : Gel strength and gel melting point are important properties of gelatin in determining the quality of the products. High gel strength values of gelatin correspond to its high economic value. The gel 
Table 2 : Comparison of proximate composition of gelatin from D. macrosoma heads with other fish species (Common carp heads, D. macrosoma skin and channel catfish head bones)

\begin{tabular}{|c|c|c|c|c|}
\hline Proximate composition (\%) & D. macrosomaheads $\mathrm{s}^{\mathrm{a}}$ & Common carp head bones ${ }^{b}$ & D. macrosoma skin ${ }^{\mathrm{C}}$ & Channel catfish head bones ${ }^{d}$ \\
\hline Moisture & $9.08 \pm 0.36$ & $15.1 \pm 0.9$ & $11.3 \pm 0.42$ & $8.3 \pm 1.9$ \\
\hline Protein & $15.25 \pm 0.11$ & $28.3 \pm 1.3$ & $68.7 \pm 0.15$ & $77.9 \pm 1.2$ \\
\hline Lipid & $0.46 \pm 0.06$ & $3.3 \pm 0.5$ & $0.22 \pm 0.02$ & $10.3 \pm 0.9$ \\
\hline Ash & $41.03 \pm 0.74$ & $51.2 \pm 1.7$ & $1.15 \pm 0.13$ & $1.3 \pm 0.5$ \\
\hline $\mathrm{pH}$ & $3.31 \pm 0.02$ & 5.30 & 4.87 & - \\
\hline
\end{tabular}

${ }^{a}$ Values obtained from current study; ${ }^{b}$ Values from Silva et al. (2011); 'Values from Cheow et al. (2007); 'Values from Liu et al. (2009)

Table 3 : Comparison of gel strength and melting point of $D$. macrosoma heads gelatine with bovine (control) and other fish species

\begin{tabular}{|c|c|c|c|}
\hline Gelatine & Gel strength (g) & Melting point $\left({ }^{\circ} \mathrm{C}\right)$ & References \\
\hline D. macrosoma heads ${ }^{\mathrm{a}}$ & 19.68 & 16 & Current study \\
\hline Bovine (control) $)^{b}$ & 300.5 & 37 & Current study \\
\hline D. macrosoma skins & 176.92 & 18.5 & Cheow et al. (2007) \\
\hline Common carp heads & $54.7-131.5$ & $24.6-27.8$ & Silva et al. (2011) \\
\hline Channel catfish head bones & $117-282$ & $23-27$ & Liu et al. (2009) \\
\hline
\end{tabular}

$\stackrel{a-b}{a-b}$ alues are the mean of duplicate samples

strength obtained from $D$. macrosoma heads gelatin conducted in this study was $19.68 \mathrm{~g}$ (Table 3). It was relatively lower than those found in D. macrosoma skin (Cheow et al., 2007), common carp head bones (Silva et al., 2011) and channel catfish head bones (Liu et al., 2009) conducted in previous studies as well as bovine gelatin, which acted as a control in this study. The low gel strength may be influenced by the $\mathrm{pH}$ that was 3.31 in this study because gel strength of all the gelatins decrease below pH 4 and slightly above $\mathrm{pH} 8$ (Choi and Regenstein, 2000). The pH of gelatin may also be affected by the washing treatment (Jakhar et al., 2012). Factors that influenced the gel strength values also include the molecular weight distribution of gelatin, size of protein chains and composition of amino acids (Sanaei et al., 2013), as well as the concentration of gelatin solution, temperature, aging time and $\mathrm{pH}$ (Kasankala et al., 2007). These factors should be further explored to improve gel strength of gelatin from D. macrosoma heads.

The melting point of gelatin obtained from the heads of $D$. macrosoma was $16^{\circ} \mathrm{C}$ (Table 3 ) and this value was found relatively close to the $D$. macrosoma skin $\left(18.5^{\circ} \mathrm{C}\right)$ as reported by Cheow et al. (2007). However, the melting point of D. macrosoma head gelatin was lower compared to bovine (control) in this study, as well as common carp heads and channel catfish head bones as reported in previous studies (Liu et al., 2009; Silva et al., 2011). Low melting point values at low $\mathrm{pH}$ were reported by Choi and Regenstein (2000), as well as Pang et al. (2014) who showed that melting points of gelatin decreased markedly at $\mathrm{pH}$ values of less than 4.0. In addition, the maturing temperature and concentration of gelatin gel have potential to affect the melting point of gelatin (Mariod and Adam, 2013).
Fish gelatins are known to have lower gel strength and melting point than mammalian gelatin, and the gel strength of fish gelatin ranges from 0 to $200 \mathrm{~g}$ (Karim and Bhat, 2009). The gelatin melted below body temperature to ensure its melt-in-mouth property (Pang et al., 2014). The lower melting point and gel strength of $D$. macrosoma heads compared to bovine (control) and other fish species may be due to lower imino acid contents. Lower imino content in gelatin leads to less proline hydroxylation (Karim and Bhat, 2009). Gelatin with low melting points can be used in microencapsulation applications, since the microencapsulation process can be carried out at lower temperatures (Karim and Bhat, 2009). Fish gelatin with low melting points can also be used in dry products such as microencapsulation of vitamins (Benjakul et al., 2012). Besides, fish gelatin that cannot form gel at room temperature can be utilized in other application that do not require high gel strength, especially in short-life products such as frozen or chilled foods to prevent syneresis and changing food texture (Benjakul et al., 2012).

Functional properties of gelatin are also associated with their chemical properties. The gel strength and melting point of gelatin depends on their molecular weight distribution and amino acid composition (See et al., 2010). The amino acid composition of $D$. macrosoma head gelatin was expressed as residues per 1000 total amino acid residues. From Table 4, the ratio of imino acids (hydroxyproline and proline) of the $D$. macrosoma head gelatin was lower than bovine gelatin, which was about 46 residues per 1000 total amino acid residues to 132 residues per 1000 total amino acid residues. Fish gelatins have lower gelling and melting temperature compared to mammalian gelatin (Karim 
Table 4 : Amino acid composition of $D$. macrosoma head and bovine gelatins (residues per 1000 total amino acid residue)

\begin{tabular}{lll}
\hline Amino acid & \multicolumn{2}{c}{ Source of gelatin } \\
\cline { 2 - 3 } & D. macrosoma head & Bovine (control) \\
\hline Glutamic acid & 89 & 97 \\
Phenylalanine & 29 & 10 \\
Tyrosine & 17 & 11 \\
Glycine & 450 & 453 \\
Proline & 32 & 82 \\
Alanine & 67 & 50 \\
Methionine & 18 & 13 \\
Hydroxyproline & 14 & 50 \\
Aspartic acid & 38 & 20 \\
Valine & 18 & 35 \\
Isoleucine & 12 & 10 \\
Leucine & 13 & 15 \\
Lysine & 109 & 106 \\
Serine & 68 & 40 \\
Histidine & 34 & 8 \\
Total & 1000 & 1000 \\
\hline
\end{tabular}

Values are means of three replicates

and Bhat, 2009). In addition, imino acids are imperative in the renaturation of gelatin subunits during gelling (Mariod and Adam, 2013). A low amount of imino acids may indicate poor gelling properties and posess a weaker gel network (Sanaei et al., 2013).

The optimal soaking time of Decapterus macrosoma heads in $0.10 \mathrm{M}$ citric acid was $8 \mathrm{hrs}$ that yielded $1.7 \%$ gelatin, which was significantly different as compared to others. The moisture, crude protein, crude fat and ash were $9.08 \%, 15.25 \%$, $0.46 \%$ and $41.03 \%$, respectively, while $\mathrm{pH}$ was 3.31 . The gel strength and melting point of $D$. macrosoma head gelatin was $19.68 \mathrm{~g}$ and $16.0^{\circ} \mathrm{C}$, respectively, whereas values obtained from bovine gelatin were $300.5 \mathrm{~g}$ and $37^{\circ} \mathrm{C}$, respectively. The imino acid ratio in $D$. macrosoma head gelatin was much lower (46 residues/1000 total amino acid residues) than bovine gelatin (132 residues/1000 total amino acid residues). Extracted $D$. macrosoma head gelatin is not suitable in applications that require higher gel strength and higher melting point. However, it can be used in application such as microencapsulation and frozen products. Different methods should be applied to extract gelatin from $D$. macrosoma heads to investigate the optimum extraction method that leads to the highest yield and gel strength.

\section{Acknowledgments}

Special thanks are extended to the Universiti Malaysia Terengganu (UMT). The authors would also like to acknowledge Maperow Sdn. Bhd. (Terengganu) for their support in providing raw materials for the experiment. Finally, huge appreciation to all the supporting staff at the School of Fisheries and Aquaculture
Sciences Labs, UMT for all the assistance and guidance throughout the research period.

\section{References}

Almeida, P.F. and S.C.D.S Lannes: Extraction and physicochemical characterization of gelatin for chicken by-product. J. Food Process. Engin., 36, 824-833 (2013).

AOAC. (2000). Official methods of analysis. $15^{\text {th }}$ Edn., Virginia, Association of Official Analytical Chemist, Inc.

Benjakul, S., P. Kittiphattanabawon and J.M. Regenstein: Fish gelatin. In $2^{\text {nd }}$ Edn., Food Biochemistry and Food Processing (Ed.: B.K. Simpson). John Wiley and Sons, Inc, pp. 388-400 (2012).

British Standard Institution (BSI): Methods for sampling and testing gelatin (physical and chemical methods). London, UK, BSI (1975).

Cheow, C.S., M.S. Norizah, Z.Y. Kyaw and N.K. Howell: Preparation and characterisation of gelatins from the skins of sin croaker (Johnius dussumieri) and shortfin scad (Decapterus macrosoma). Food Chem., 101, 386-391 (2007).

Cho, S.M., K.S. Kwak, D.C.Park, Y.S. Gu, C.I. Ji, D.H. Jang, Y.B. Lee and S.B. Kim: Processing optimization and functional properties of gelatin from shark (Isurus oxyrinchus) cartilage. Food Hydrocolloid, 18, 573-579 (2004).

Choi, S.S. and J.M. Regenstein: Physicochemical and sensory characteristics of fish gelatin. J. Food Sci., 65, 194-199 (2000).

Darmanto, Y.S., T.W. Agustini, F. Swastawati and I. Al Bulushi: The effect of fish bone collagens in improving food quality. Inter. Food Res. J., 21, 891-896 (2014).

GME: Standard methods for the testing of edible gelatin, gelatin monograph. gelatin Manufacturers of Europe (2005).

GMIA: gelatin handbook. gelatin manual of the Gelatin Manufacturers Institute of America, Inc (2012).

Gómez-Guillén, M.C., M. Pérez-Mateos, J. Gómez-Estaca, E. LópezCaballero, B. Giménez and P. Montero: Fish gelatin, a renewable material for developing active biodegradable films. Tren. Food Sci. Technol., 20, 3-16 (2009).

Gudmundsson, M. and H. Hafsteinsson: Gelatin from cod skins as affected by chemical treatments. J. Food Sci., 62, 37-40 (1997).

Jakhar, J.K., A.D. Reddy, S. Maharia, H.M. Devi, G.V.S. Reddy and G. Venkateshwarlu: Characterization of fish gelatin from blackspotted croaker (Protonibea diacanthus). Arch. Appl. Sci. Res., 4, 13531358 (2012).

Jamilah, B. and K.G. Harvinder: Properties of gelatins from skins of fishblack tilapia (Oreochromis mossambicus) and red tilapia (Oreochromis nilotica). Food Chem., 77, 81-84 (2002).

Karim, A.A. and R. Bhat: Fish gelatin, properties, challenges and prospects as an alternative to mammalian gelatins. Food Hydrocolloids, 23, 563-576 (2009).

Kasankala, L.M., Y. Xue, Y., Weilong, S.D. Hong and Q. He: Optimization of gelatin extraction from grass carp (Catenopharyngodon idella) fish skin by response surface methodology. Biores. Technol., 98, 3338-3343 (2007).

Kim, S.K. and J. Venkatesan: Introduction to seafood processing byproducts. In: Seafood Processing By-Products (Ed.: S.K. Kim). New York: Springer Science Business Media (2014).

Kim, S.K. and I. Wijesekara: Industry perspectives and commercial trends for food proteins and biopeptides. In: Food proteins and peptides: chemistry, functionality, interactions and commercialization (Eds.: N.S. Hettiarachchy, K. Sato, M.R. Marshall and A. 
Kannan). CRC Press, pp. 413-415(2012).

López-Caballero, M.E., B. Giménez, M.C. Gómez-Guillén and P. Montero: Valorization \& integral use of seafood by-products. In: Engineering aspects of food biotechnology (Eds.: J. A. Teixeira and A. A. Vicente). CRC Press, pp. 374-376 (2013).

Liu, D., M. Nikoo, G. Boran, P. Zhou and J.M. Regenstein: Collagen and gelatin. Annual Rev. Food Sci. Technol., 6, 527-550 (2015).

Liu, D.C., Y.K. Lin and M.T. Chen: Optimum condition of extracting collagen from chicken feet and its characteristics. Asian-Australas. J. Animal Sci., 14, 1638-1644 (2011).

Liu, H., D. Li and S. Guo: Studies on collagen from the skin of channel catfish (Ictalurus punctaus). Food Chem., 101, 621-625 (2007).

Liu, H.Y., J. Han and S.D. Guo: Characteristics of the gelatin extracted from channel catfish (Ictalurus punctatus) head bones. LWT - Food Sci. Technol., 42, 540-544 (2009).

Mariod, A.A. and H.F. Adam: Review: Gelatin, source, extraction and industrial applications. Acta Sci. Pol. Technol. Aliment., 12, 135$147(2013)$.

Montero, P. and M.C. Gómez-Guillén: Extracting conditions for megrim (Lepidorhombus boscii) skin collagen affect functional properties of the resulting gelatin. J. Food Sci., 65, 434-438 (2000).

Mohtar, N.F., C. Perera and S.Y. Quek: Optimisation of gelatin extraction from hoki (Macruronus novaezelandiae) skins and measurement of gel strength and SDS-PAGE. Food Chem., 122, 307-313 (2010).

Muyonga, J.H., C.G.B. Cole and K.G. Duodu: Extraction and physicochemical characterisation of Nile perch (Lates niloticus) skin and bone gelatin. Food Hydrocolloids, 18, 581-592 (2004).

Ninan, G., A.A. Zynudheen, A. John, P.K. Binsi and C.G. Joshy: Effect of pretreatment conditions and bleaching on physico-chemical and functional properties of gelatin prepared from cuttlefish skin. Ind. J. Fish., 62, 62-69 (2015).

Omar, M.M., S.S.A. Rashid and M.S.A. Karim: Sustaining traditional food, Malaysia's high-protein snack 'keropok lekor'. Cluster of Tourism Research. University Putra Malaysia, Selangor, pp. 28-31 (2008).

Pang, Z., H. Deeth, P. Sopade, R. Sharma and N. Bansal: Rheology, texture and microstructure of gelatin gels with and without milk proteins. Food Hydrocolloids, 35, 484-493 (2014).

Puspitasari, D.A.P., V.P. Bintoro and B.E. Setiani: The soaking effect on different hydrochloride acid level and soaking time on $\mathrm{pH}$, swelling percentage and collagen yield of chicken shank bone. J. Indones. Trop. Anim. Agricult., 38, 98-102 (2013).

Sanaei, A.V., F. Mahmoodani, S.F. See, S.M. Yusop and A.S. Babji. Optimization of gelatin extraction and physico-chemical properties of catfish (Clarias gariepinus) bone gelatin. Inter. Food Res. J., 20, 423-430 (2013).

See, S.F., P.K. Hong, K.L. Ng, W.M. Wan Aida and A.S. Babji: Physicochemical properties of gelatins extracted from skins of different freshwater fish species. Inter. Food Res. J., 17, 809-816 (2010).

Shakila, R.J., E. Jeevithan, A. Varatharajakumar, G. Jeyasekaran and D. Sukumar: Functional characterization of gelatin extracted from bones of red snapper and grouper in comparison with mammalian gelatin. LWT-Food Sci. Technol., 48, 30-36 (2012).

Silva, R.S.G.D., S.F. Bandeira, F.C. Petry and L.A.A. Pinto: Effect of bone particle size of carp (Cyprinus carpio) heads in the gelatin extraction. Vetor, Rio Grande, 21, 34-43 (2011).

Tabarestani, H.S., Y. Maghsoudlou, A. Motamedzadegan and A.R.S. Mahoonak: Optimization of physico-chemical properties of gelatin extracted from fish skin of rainbow trout (Onchorhynchus mykiss). Biores. Technol., 101, 6207-6214 (2010).

Tavakolipour, H.: Extraction and evaluation of gelatin from silver carp waste. World J. Fish Mar. Sci., 3, 10-15 (2011).

The Star Online: Malaysians eat more fish than Japanese, reveals study: http://www.thestar.com.my/News/Nation/2014/06/19/Malaysianseat-more-fish-than-Japanese-reveals-study/ Accessed 15.10.10 (2014).

Villas-Bôas S.G., D.G. Delicado, M. Åkesson and J. Nielsen: Simultaneous analysis of amino and non-amino organic acids as methyl chloroformate derivatives using gas chromatographymass spectrometry. Analyt. Biochem., 322, 134-138 (2003).

Zhou, P. and J.M. Regenstein: Effects of alkaline and acid pretreatment on Alaska pollock skin gelatin extraction. J. Food Sci., 70, 392-396 (2005). 